\title{
Comparison of open and minimally invasive surgery for intradural-extramedullary spine tumors
}

\author{
Albert P. Wong, MD, ${ }^{1}$ Rishi R. Lall, MD, ${ }^{2}$ Nader S. Dahdaleh, MD, ${ }^{2}$ Cort D. Lawton, MD, ${ }^{2}$ \\ Zachary A. Smith, MD, ${ }^{2}$ Ricky H. Wong, MD, ${ }^{3}$ Michael J. Harvey, MD, ${ }^{2}$ Sandi Lam, MD, ${ }^{4}$ \\ Tyler R. Koski, MD, ${ }^{2}$ and Richard G. Fessler, MD, PhD ${ }^{5}$
}

1Department of Neurosurgery, Stanford University School of Medicine, Stanford, California; ${ }^{2}$ Department of Neurosurgery, Northwestern University Feinberg School of Medicine, Chicago; ${ }^{3}$ Department of Neurosurgery, University of Chicago Pritzer School of Medicine, Chicago, Illinois; ${ }^{4}$ Department of Neurosurgery, Baylor College of Medicine, Houston, Texas; and ${ }^{5}$ Department of Neurosurgery, Rush University Medical Center, Chicago, Illinois

OBJECT Patients with symptomatic intradural-extramedullary (ID-EM) tumors may be successfully treated with resection of the lesion and decompression of associated neural structures. Studies of patients undergoing open resection of these tumors have reported high rates of gross-total resection (GTR) with minimal long-term neurological deficit. Case reports and small case series have suggested that these patients may be successfully treated with minimally invasive surgery (MIS). These studies have been limited by small patient populations. Moreover, there are no studies directly comparing perioperative outcomes between patients treated with open resection and MIS. The objective of this study was to compare perioperative outcomes in patients with ID-EM tumors treated using open resection or MIS.

METHODS A retrospective review was performed using data collected from 45 consecutive patients treated by open resection or MIS for ID-EM spine tumors. These patients were treated over a 9-year period between April 2003 and October 2012 at Northwestern University and the University of Chicago. Statistical analysis was performed to compare perioperative outcomes between the two groups.

RESULTS Of the 45 patients in the study, 27 were treated with the MIS approach and 18 were treated with the open approach. Operative time was similar between the two groups: 256.3 minutes in the MIS group versus 241.1 minutes in the open group ( $p=0.55)$. Estimated blood loss was significantly lower in the MIS group (133.7 $\mathrm{ml}$ ) compared with the open group $(558.8 \mathrm{ml})(p<0.01)$. A GTR was achieved in $94.4 \%$ of the open cases and $92.6 \%$ of the MIS cases $(p=0.81)$. The mean hospital stay was significantly shorter in the MIS group ( 3.9 days) compared with the open group (6.1 days) ( $p$ $<0.01)$. There was no significant difference between the complication rates $(p=0.32)$ and reoperation rates $(p=0.33)$ between the two groups. Multivariate analysis demonstrated an increased rate of complications in cervical spine tumors (OR 15, $p=0.05$ )

CONCLUSIONS Thoracolumbar ID-EM tumors may be safely and effectively treated with either the open approach or an MIS approach, with an equivalent rate of GTR, perioperative complication rate, and operative time. Patients treated with an MIS approach may benefit from a decrease in operative blood loss and shorter hospital stays.

http://thejns.org/doi/abs/10.3171/2015.5.FOCUS15129

KEY WORDS intradural tumor; extramedullary tumor; spine tumor; intradural-extramedullary tumor; minimally invasive surgery; spine surgery

ABBREVIATIONS ASIA = American Spinal Injury Association; EBL = estimated blood loss; GTR = gross-total resection; ID-EM = intradural-extramedullary; MIS = minimally invasive surgery.

SUBMITTED March 12, 2015. ACCEPTED May 7, 2015.

INCLUDE WHEN CITING DOI: 10.3171/2015.5.FOCUS15129.

DISCLOSURE The authors have no direct financial disclosures to note in the presentation of this work. Dr. Fessler was the principal investigator of a research grant awarded to the Northwestern University Feinberg School of Medicine by Medtronic PS Medical (Memphis, TN) for the development of minimally invasive spine surgical procedures. Dr. Fessler also receives royalties from DePuy, Stryker, and Medtronic; however, these are not related to minimally invasive techniques and technologies. Dr. Koski is a consultant for Medtronic, NuVasive, and Spine Wave, and he owns stock in NuVasive. 
I NTRADURAL-EXTRAMEDULLARY (ID-EM) spine tumors are rare, occurring in 5 to 10 per 100,000 people..$^{12,25,31}$ The most common ID-EM tumors include meningiomas, schwannomas, and neurofibromas. ${ }^{32}$ Although IDEM tumors are usually benign, they may be associated with progressive pain or neurological deficit. Cervical or thoracic tumors may present with neck or upper back pain, radicular symptoms, or myelopathy. Tumors of the lumbar region may present with low-back pain, leg pain, lowerextremity weakness, or bowel or bladder dysfunction. ${ }^{32}$

Symptomatic patients with ID-EM tumors are treated successfully with resection of the lesion and decompression of associated neural structures. Traditional open surgical approaches use a lengthy midline incision, subperiosteal dissection of the paraspinal muscles, bilateral laminectomies, and intradural tumor resection. Previous series on open resection of ID-EM tumors have reported high rates of gross-total resection (GTR) with minimal long-term neurological deficit. . $^{1323}$

In recent years, minimally invasive surgery (MIS) approaches have become increasingly popular for treatment of spinal pathology, due to the extensive soft-tissue dissection and disruption of midline structures associated with open surgical approaches. ${ }^{28}$ For patients with degenerative pathology, MIS approaches have been associated with decreased operative blood loss, diminished narcotic use, shorter postoperative stay, and lower costs of hospitalization relative to open surgery. ${ }^{4,10,34}$ Additionally, biomechanical studies have suggested that MIS approaches may result in less spinal destabilization than open procedures in patients with both degenerative and intradural pathology. 3,21

There have been prior reports of MIS for ID-EM tumors; however, these have been limited to case reports or small series. 6,9,22,26 Furthermore, to our knowledge, no previous study has directly compared MIS and open approaches for ID-EM lesions. The goal of this study was to compare perioperative outcomes in patients with ID-EM tumors treated by MIS versus open resection.

\section{Methods}

We performed a retrospective review of prospectively collected data on 45 consecutive patients treated by MIS or open resection for ID-EM spine tumors over a 9-year period between April 2003 and October 2012 at two university practices. Approval from both institutional review boards was obtained prior to conducting the study. Demographic data were recorded, including age, sex, type of approach (MIS or open), location of the tumor, number of spinal levels involved, and the tumor pathology. Baseline patient characteristics were recorded and listed in Table 1.

In both the MIS and open approaches, perioperative data were collected for the following: estimated blood loss (EBL); duration of surgery; necessity for spinal fusion; days of flat bed rest; perioperative complications; necessity for a lumbar drain as well as the number of days of CSF drainage; whether a revision surgery was performed (postoperative hematoma, CSF leak repair, tumor recurrence); disposition status at discharge (home vs inpatient rehabilitation); and length of hospital stay. Statistical anal-
TABLE 1. Demographic data in 45 patients with ID-EM tumors*

\begin{tabular}{|c|c|c|c|c|}
\hline \multirow[b]{2}{*}{ Variable } & \multirow[b]{2}{*}{ Total } & \multicolumn{2}{|c|}{ Op Approach } & \multirow{2}{*}{$\begin{array}{c}\mathrm{p} \\
\text { Value }\end{array}$} \\
\hline & & Open & MIS & \\
\hline $\begin{array}{l}\text { Mean age in yrs } \pm S D \\
\text { (range) }\end{array}$ & $50.8 \pm 12.2(29-79)$ & 51.6 & 50.3 & 0.73 \\
\hline Sex & & & & 0.27 \\
\hline Female & $20(44.4)$ & 9 & 11 & \\
\hline Male & $25(55.6)$ & 9 & 16 & \\
\hline Spinal level & & & & 0.01 \\
\hline Cervical & $11(24.4)$ & 9 & 2 & \\
\hline Thoracic & $9(20.0)$ & 2 & 7 & \\
\hline Lumbar & $24(53.3)$ & 7 & 17 & \\
\hline Lumbosacral & $1(2.2)$ & 0 & 1 & \\
\hline No. of spinal levels & & & & 0.02 \\
\hline 1 & $7(15.6)$ & 0 & 7 & \\
\hline 2 & $38(84.4)$ & 18 & 20 & \\
\hline $\begin{array}{l}\text { Mean no. of spinal } \\
\text { levels } \pm \text { SD }\end{array}$ & $1.84 \pm 0.37$ & 2.00 & 1.74 & 0.02 \\
\hline Presenting symptoms & & & & 0.23 \\
\hline Back pain & $7(15.6)$ & 1 & 6 & \\
\hline Extremity sensory & $15(33.3)$ & 9 & 6 & \\
\hline Weakness & $1(2.2)$ & 0 & 1 & \\
\hline $\begin{array}{l}\text { Both back pain \& } \\
\text { sensory }\end{array}$ & $22(48.9)$ & 8 & 14 & \\
\hline Pathology & & & & 0.52 \\
\hline Nerve sheath tumor & $28(62.2)$ & 12 & 16 & \\
\hline Meningioma & $10(22.2)$ & 5 & 5 & \\
\hline Congenital & $3(6.7)$ & 1 & 2 & \\
\hline Paraganglioma & $1(2.2)$ & 0 & 1 & \\
\hline Other & $3(6.7)$ & 0 & 3 & \\
\hline $\begin{array}{l}\text { Mean follow-up in mos } \\
\pm \mathrm{SD} \text { (range) }\end{array}$ & $14.9 \pm 13.9(1-56)$ & 13.1 & 16.0 & 0.50 \\
\hline
\end{tabular}

yses were conducted using bivariate analysis (Student ttest and chi-square test). A multivariate analysis was also performed to control for the location of the spine tumor as well as the number of spinal levels involved.

The open approach is achieved with a midline incision over the spinous processes, followed by subperiosteal dissection to expose the lamina laterally up to the facet joints. The bilateral lamina and ligaments are removed above and below the border of the tumor until the dura is completely exposed. The operating microscope is brought in for the dural incision, and the edges of the thecal sac are tacked up to the paraspinal muscles with 4-0 Nurolon sutures. The tumor is resected with standard microsurgical techniques and the dura is closed with a running 4-0 Nurolon suture. The fascia is closed with absorbable 0 Vicryl sutures and the subcutaneous layer is closed with 2-0 Vicryl, followed by staples to close the skin. The decision to include spinal instrumentation and fusion for possible spinal instability is made by each individual surgeon during surgery.

The MIS approach starts with an incision $1.5 \mathrm{~cm}$ lateral to the midline and localized over the center of the 
tumor, as confirmed by intraoperative fluoroscopy and preoperative MRI. The fascia is incised, followed by blunt dissection with a finger sweep and Metzenbaum scissors. The smallest muscle dilator tube is guided onto the lamina with the surgeon's finger. Sequential dilation is performed, with serial tubes being placed until the final expandable retractor (Quadrant, Medtronic) is secured and its location confirmed by fluoroscopy. The retractor is expanded in the rostral-caudal and medial-lateral directions until fluoroscopy shows that the retractor blades border the expected superior-inferior poles of the tumor. The remainder of the soft tissue is removed with electrocautery, and a curved high-speed drill is used to perform the ipsilateral laminectomies. The retractor tube is angled medially, and the base of the spinous processes and contralateral lamina are decompressed with the drill and Kerrison rongeurs. The dura is opened in the midline with a long-handled no. 15 blade scalpel. The operating microscope is brought in for the dural incision and the edges of the thecal sac are tacked up to the paraspinal muscles with 4-0 Nurolon sutures. The tumor is resected with standard microsurgical techniques and the dura is closed with a running 4-0 Nurolon suture. The fascia is closed with absorbable 0 Vicryl sutures and the subcutaneous layer closed with 3-0 Vicryl sutures. The dermis is closed with a running 4-0 absorbable suture followed by a skin adhesive.

\section{Results}

Data were analyzed in 45 consecutive patients, including 27 patients treated with the MIS approach and 18 treated with the open approach. The mean age was similar in the MIS group (50.3 years) compared with the open group (51.6 years). Sex distribution was similar between the two groups: $59.2 \%$ males in the MIS group and 50\% in the open group. The most common surgical level in the MIS group was the lumbar level (62.9\%), and the most common surgical level for the open group was the cervical $(50 \%)(\mathrm{p}=0.01)$. The open cohort incorporated at least 2 spinal levels in $100 \%$ of the patients, compared with $74.1 \%$ in the MIS cohort $(p=0.02)$. In the MIS cohort the patients most frequently presented with both back pain and sensory deficits. In the open cohort the patients presented most frequently with paresthesias in the extremities. The most common diagnosis for both groups was nerve sheath tumor, followed by meningioma. A subgroup analysis comparing only 2-level ID-EM spine tumors in the open $(n=18)$ and MIS $(n=20)$ cohorts demonstrated no significant difference in perioperative complication rates $(\mathrm{p}=$ 0.50 ). The mean follow-up time was 14.9 months (Table 1).

The mean operative time was similar between the two groups: 256.3 minutes in the MIS group and $241.1 \mathrm{~min}-$ utes in the open group. The EBL was significantly lower in the MIS group (133.7 ml) relative to the open group (558.8 $\mathrm{ml})(\mathrm{p}<0.01)$. Instrumented fusion was required in $11.1 \%$ of patients in the open group and in none of those in the MIS group. A GTR, as determined by postoperative MRI, was achieved in $92.6 \%$ of patients in the MIS group and in $94.4 \%$ of those in the open group (Table 2).

The average hospital stay for the MIS cohort was 3.9 days, compared with 6.1 days for the open cohort $(\mathrm{p}<$ 0.01 ). No patients in the MIS group required periopera- tive blood transfusions, compared with $11.1 \%$ of those in the open group. A lumbar drain was placed in only 1 patient in the MIS group (3.7\%) for 3 days for CSF diversion. In contrast, a lumbar drain was placed in 7 of the patients in the open group (38.9\%) for a mean duration of 6 days $(\mathrm{p}<0.01)$. Two patients in the MIS group had an improved American Spinal Injury Association (ASIA) score postoperatively. The remaining MIS patients had a preoperative ASIA E (normal) score. No worsening of the preoperative baseline score occurred in the MIS group. In contrast, 6 patients in the open group had an improved ASIA score whereas 2 patients in the open group had a negative change in their ASIA score $(p=0.05)$ (Table 3$)$.

A total of 7 patients had a perioperative complication; 4 surgical and 3 medical. Four complications occurred in the open group (22.2\%) compared with 3 complications in the MIS group (11.1\%). The most common perioperative complication was CSF leak. Two patients (11.1\%) in the open group required reoperation for CSF leak, compared with 1 patient (3.7\%) in the MIS group. Indications for reoperation included debulking of residual tumor, evacuation of epidural hematoma, CSF leak repair, and hardware failure. There were no deaths in our series (Table 4).

\section{Discussion}

An ID-EM spine tumor is traditionally resected with a classic midline, open approach. Open approaches, however, typically involve multilevel disruption of the soft-tissue attachments and ligaments to the lamina and spinous processes, as well as wide bilateral laminectomies above and below the level of the tumor. ${ }^{13,23}$ The MIS approach to spinal pathology has recently gained increasing popularity due to reports of decreased operative blood loss, shorter hospital stay, and equivalent neurological outcomes relative to open surgery. ${ }^{4,10,20,27}$ Of note, however, these studies have primarily focused on patients with degenerative pathology.

In the present study, we compared perioperative outcomes in patients with ID-EM tumors undergoing either open or MIS resection. Of the 45 patients included in this study, 27 were treated by the described MIS approach, compared with 18 treated by the traditional open approach. Patient demographics were similar between both surgical groups, including age, sex distribution, and preoperative symptoms. Similarly, there was no significant difference in the perioperative data between the two groups for mean operative time, use of microscope for visualization, achievement of GTR, final pathological findings, or fusion rate. The 2 patients in the open group requiring spinal fusion had tumor extension into the foramen requiring complete ipsilateral facetectomy. Due to concern for potential spinal instability, the fusion was planned preoperatively by the surgeon. A GTR was achieved in the majority of patients except in cases in which intraoperative pathological investigation demonstrated metastatic cancer and the surgical plan was changed to palliative subtotal resection. Significant differences comparing the two groups were found in operative blood loss, postoperative CSF leak, lumbar drain placement and duration, change in ASIA score, and length of hospital stay.

Successful minimally invasive resection of intradural 
TABLE 2. Intraoperative data in 45 patients with ID-EM tumors*

\begin{tabular}{|c|c|c|c|c|}
\hline \multirow[b]{2}{*}{ Variable } & \multirow[b]{2}{*}{ Total } & \multicolumn{2}{|c|}{ Op Approach } & \multirow[b]{2}{*}{$\mathrm{p}$ Value } \\
\hline & & Open & MIS & \\
\hline \multicolumn{5}{|l|}{ Surgical technique } \\
\hline Open & $18(40.0)$ & & & \\
\hline MIS & $27(60.0)$ & & & \\
\hline Approach & & & & $<0.01$ \\
\hline Unilateral & $29(64.4)$ & 2 & 27 & \\
\hline Bilateral & $16(35.6)$ & 16 & 0 & \\
\hline Visualization & & & & 0.21 \\
\hline Loupes & $1(2.2)$ & 1 & 0 & \\
\hline Microscope & $44(97.8)$ & 17 & 27 & \\
\hline GTR & & & & 0.81 \\
\hline No & $3(6.7)$ & 1 & 2 & \\
\hline Yes & $42(93.3)$ & 17 & 25 & \\
\hline Fusion & & & & 0.08 \\
\hline No & $43(95.6)$ & 16 & 27 & \\
\hline Yes & $2(4.4)$ & 2 & 0 & \\
\hline Mean EBL in ml (range) & $301.7(25-2100)$ & 558.8 & 133.7 & $<0.01$ \\
\hline $\pm S D$ & 460.3 & 631.8 & 161.7 & \\
\hline $95 \% \mathrm{Cl}$ & & $234.0-883.7$ & $68.3-199.0$ & \\
\hline Mean OR time in mins (range) & $250.2(113-445)$ & 241.1 & 256.3 & 0.55 \\
\hline $\pm S D$ & 83.2 & 79.9 & 86.3 & \\
\hline $95 \% \mathrm{Cl}$ & & $201.3-280.8$ & $222.2-290.4$ & \\
\hline
\end{tabular}

spinal cord tumors has been previously described..$^{20,27,33,36}$ In 2006, Tredway et al. reported on 6 patients with IDEM spinal cord tumors who underwent MIS through a small paramedian incision with use of a tubular retractor system..$^{33}$ In this small series, they reported excellent outcomes with a $100 \%$ rate of GTR and no perioperative complications. Their reported mean EBL was minimal, at $56 \mathrm{ml}$ per case. In contrast, in a prior comparison of "mini-open" versus open techniques for resection of intradural tumors, Lu et al. reported a mean EBL of $372 \mathrm{ml}$ with a traditional open approach.$^{14}$ In the present series, we found a significant decrease in EBL with an MIS approach $(133.7 \mathrm{ml})$ relative to the open group $(558.8 \mathrm{ml})$ $(\mathrm{p}<0.01)$. As a result, no patients in the MIS group required perioperative blood transfusions, compared with 2 patients $(11.1 \%)$ in the open group. This difference may be due to the unilateral, muscle-splitting approach used in MIS techniques that minimizes bleeding from soft-tissue dissection. The expandable tubular retractor serves not only to open the surgical field, but functions as a physical tamponade against soft-tissue bleeding during the operation. Similarly, the smaller incision afforded by an MIS tubular approach may lead to a decrease in soft-tissue dissection and operative blood loss.

Regardless of the surgical approach, complete resection of the ID-EM tumor is one of the primary surgical goals. The literature suggests that GTR in open approaches ranges from $74 \%$ to $92 \%$ of cases., ${ }^{27,11,15-17,19,24,29}$ The MIS or mini-open techniques have achieved similar rates of
GTR in the literature, ranging from $80 \%$ to $94 \% . .^{14,20,36} \mathrm{In}$ our study, the GTR rate of ID-EM was feasible through a true MIS approach, with a $92.6 \%$ rate of GTR, comparable to prior open and mini-open series., ${ }^{9,13,14,23} \mathrm{~A}$ similar GTR rate was also achieved with the open approach in our patients (94.4\%), suggesting that either technique demonstrates good results.

Resection of an ID-EM tumor requires meticulous closure of the durotomy to minimize the risks of postoperative CSF leak symptoms. In most MIS cases, the tubular approach decreases the probability of a postoperative symptomatic CSF leak due to the limited soft-tissue exposure and apposition of the surgical layers. This minimizes the surgical cavity and tamponades against potential accumulation of a pseudomeningocele. In the literature, the CSF leak rate in ID-EM tumor resections ranges from $0 \%-5 \%$ in MIS cases to 0\%-9\% in open cases. ${ }^{8,13,14,18,23,33}$ In our study, the MIS group had a statistically significant decrease in the CSF leak rate of $3.7 \%$ compared with the open group leak rate of $16.7 \%(p=0.03)$. A lumbar drain was placed in all of the patients with clinical evidence of postoperative symptomatic CSF leakage (postural headaches or extravasation of CSF beyond the skin). The mean lumbar drain duration was 3 days in the MIS group and 6 days in the open group. Despite the technical difficulty of suturing the thecal sac tight through a tubular retractor, the MIS group appeared to have a lower rate of postoperative symptomatic CSF leakage. The smaller surgical cavity or dead space decreases the risk of a CSF leak or the 
TABLE 3. Perioperative data in 45 patients with ID-EM tumors*

\begin{tabular}{|c|c|c|c|c|}
\hline \multirow[b]{2}{*}{ Variable } & \multirow[b]{2}{*}{ Total } & \multicolumn{2}{|c|}{ Op Approach } & \multirow[b]{2}{*}{ p Value } \\
\hline & & Open & MIS & \\
\hline Transfusion & & & & 0.08 \\
\hline No & $43(95.6)$ & 16 & 27 & \\
\hline Yes & $2(4.4)$ & 2 & 0 & \\
\hline Lumbar drain & & & & $<0.01$ \\
\hline No & $37(82.2)$ & 11 & 26 & \\
\hline Yes & $8(17.8)$ & 7 & 1 & \\
\hline Lumbar drain (no. of days) & & & & $<0.01$ \\
\hline 0 & $37(82.2)$ & 11 & 26 & \\
\hline 3 & $1(2.2)$ & 0 & 1 & \\
\hline 4 & $2(4.4)$ & 2 & 0 & \\
\hline 5 & $1(2.2)$ & 1 & 0 & \\
\hline$\geq 6$ & $4(8.9)$ & 4 & 0 & \\
\hline Mean no. of days \pm SD (range) & $5.5 \pm 2.9(0-10)$ & 6 & 3 & \\
\hline Examination findings after op & & & & 0.12 \\
\hline Same & $40(88.9)$ & 17 & 23 & \\
\hline Worse & $4(8.9)$ & 0 & 4 & \\
\hline Better & $1(2.2)$ & 1 & 0 & \\
\hline Preop to postop change in ASIA score & & & & 0.05 \\
\hline-1 & $2(4.4)$ & 2 & 0 & \\
\hline 0 & $35(77.8)$ & 10 & 25 & \\
\hline 1 & $6(13.3)$ & 4 & 2 & \\
\hline 2 & $1(2.2)$ & 1 & 0 & \\
\hline 4 & $1(2.2)$ & 1 & 0 & \\
\hline Mean \pm SD (range) & $0.22 \pm 0.77(-1$ to 4$)$ & 0.44 & 0.07 & 0.11 \\
\hline Mean hospital stay in days (range) & $4.76(1-13)$ & 6.10 & 3.90 & $<0.01$ \\
\hline$\pm \mathrm{SD}$ & 2.74 & 3.1 & 2.2 & \\
\hline $95 \% \mathrm{Cl}$ & & $4.53-7.58$ & $3.04-4.74$ & \\
\hline Mean hospital stay in days, $w /$ respect to lumbar drain & & & & $<0.01$ \\
\hline w/o lumbar drain & $4.14 \pm 2.35$ & & & \\
\hline w/ lumbar drain & $7.63 \pm 2.72$ & & & \\
\hline Disposition & & & & 0.87 \\
\hline Home & $37(82.2)$ & 15 & 22 & \\
\hline Rehabilitation facility & $8(17.8)$ & 3 & 5 & \\
\hline
\end{tabular}

need for a lumbar drain. This appears to be an advantage of the MIS approach in resection of an ID-EM tumor.

Another reported benefit of MIS approaches is a decrease in hospital duration. Some hypothesize that the smaller incision length and decreased soft-tissue dissection result in lower postoperative pain. $4,6,8-10,14,20,22,33,35$ Improved pain control would minimize the sedating side effects associated with narcotics that may prolong the patient's recovery period. In addition, the increased rate of postoperative CSF leakage and lumbar drain placement in open cases increases the hospitalization time. In the present study, the MIS group had a significantly lower mean duration of hospital stay (3.9 days) relative to the open group (6.1 days) $(\mathrm{p}<0.01)$. This is comparable to the reported hospitalization time found in the literature for both patients with MIS and those with open procedures undergoing ID-EM tumor resection (2.3-4.9 days vs 4.1-6.3 days). $8,13,14,33,36$

Resecting an ID-EM spine tumor can potentially result in a worsening of neurological function. The ASIA scale was used to assess the patient's neurological examination pre- and postoperatively. The majority of the patients in both the MIS and open groups were ASIA E before and after surgery. The open group had 2 patients who developed postoperative weakness and 6 patients who improved after surgery. Of the patients with perioperative changes in their ASIA score, two-thirds had cervicothoracic ID-EM tumors. Compression of the spinal cord from ID-EM tumors carries higher risk of neurological injury compared with ID-EM tumors in the lumbar region, where nerve 
TABLE 4. Complications in 45 patients with ID-EM tumors

\begin{tabular}{lcrrrr} 
& & \multicolumn{2}{c}{ Op Approach } & \\
\cline { 3 - 4 } Variable & Total No. (\%) & Open & MIS & p Value \\
\hline Complications & & & & 0.32 \\
\hline None & $38(84.4)$ & 14 & 24 & \\
\hline Surgical & $4(8.9)$ & 3 & 1 & \\
\hline Medical & $3(6.7)$ & 1 & 2 & \\
\hline Surgical complications & & & & \\
\hline CSF leak & 4 & 3 & 1 & \\
\hline Medical complications & & & & \\
\hline HCAP & 1 & 0 & 1 & \\
\hline Wound dehiscence & 1 & 0 & 1 & \\
\hline Troponin elevation & 1 & 1 & 0 & \\
\hline CSF leak & & & & 0.03 \\
\hline No & $41(91.1)$ & 15 & 26 & \\
\hline Yes & $4(8.9)$ & 3 & 1 & \\
\hline Reop & & & & 0.33 \\
\hline No & $42(93.3)$ & 16 & 26 & \\
\hline Yes & $3(6.7)$ & 2 & 1 & \\
\hline Reop indication & & & & \\
\hline CSF repair & 3 & 2 & 1 & \\
\hline
\end{tabular}

$\mathrm{HCAP}=$ health care-associated pneumonia

roots have greater tolerance to compression injury and surgical manipulation. Multiple authors have described modified paramedian approaches to minimize manipulation of the spinal cord and the potential risk of postoperative neurological deficit. ${ }^{1,5,30}$ Mehta et al. reported that their postoperative neurological deficits were highest in patients with ID-EM tumors located in the upper thoracic spine. They postulated that the high spinal cord to canal space ratio and limited watershed blood supply zones all may contribute to a higher risk of postoperative neurological deficit. ${ }^{18}$ This may explain the elevated number of patients with perioperative neurological deficits in the open cohort, because $61.1 \%$ of the patients had cervicothoracic ID-EM tumors. This suggests that the open cohort surgeries may have been more difficult due to the location of the cervical ID-EM tumors as well as the diminished preoperative neurological condition.

The limitation in this paper is the retrospective comparison design, which may potentially allow for bias. We included consecutive patients with ID-EM tumors spanning 1 or 2 levels from the cervical, thoracic, and lumbar spine over a time period of 9 years. Nonetheless, the majority of the ID-EM tumors were located in the lumbar region for the MIS group (62.9\%) and in the cervical region for the open group (50\%). This may explain the differences in perioperative ASIA scores between the two groups. Although the open cervical group had a higher perioperative complication rate compared with the MIS group, this may be due to the larger subpopulation of patients who underwent open procedures. We performed a multivariate analysis to control for the difference in the number of spinal levels and location of ID-EM tumors between the MIS and open cohorts. We found no statistical difference in regard to the number of spinal levels between the two groups. However, when comparing the cervical ID-EM tumors to thoracolumbar ID-EM tumors, the odds ratio for perioperative complications was significantly higher in cervical lesions (OR 15, $\mathrm{p}=0.05$ ).

Although our data suggest that an MIS approach for thoracolumbar spine tumors is safe and similar in outcomes compared with an open approach, there are insufficient data to make a conclusion for cervical spine tumors treated with MIS. There also is the potential for selection bias, because one surgeon used only MIS techniques whereas the other surgeons performed only open approaches to ID-EM tumors. However, all the surgeons had more than 9 years of experience. This highlights an important limitation of this study as well as the current ID-EM tumor literature; namely the absence of randomization. Future prospective randomized studies would allow for a more direct comparison of open and MIS approaches to ID-EM lesions. Nonetheless, this study represents the largest reported series thus far comparing open and MIS resection of ID-EM tumors.

\section{Conclusions}

Our findings suggest that ID-EM tumors may be safely and effectively treated via either the traditional open approach or an MIS approach. An MIS approach to thoracolumbar ID-EM spine tumors has similar perioperative complications and GTR rates compared with an open approach; however, there is insufficient evidence to recommend for or against an MIS approach to cervical spine tumors. It may be judicious to develop proficiency in thoracolumbar tumors with new surgical techniques prior to resecting cervical lesions. In this study, we found that patients in the MIS group had significantly lower EBL and a shorter postoperative hospital stay. Future studies of larger population groups with more evenly distributed pathologies, conducted in a randomized fashion, would be invaluable.

\section{References}

1. Acosta FL Jr, Aryan HE, Chi J, Parsa AT, Ames CP: Modified paramedian transpedicular approach and spinal reconstruction for intradural tumors of the cervical and cervicothoracic spine: clinical experience. Spine (Phila Pa 1976) 32:E203-E210, 2007

2. Angevine PD, Kellner C, Haque RM, McCormick PC: Surgical management of ventral intradural spinal lesions. J Neurosurg Spine 15:28-37, 2011

3. Bresnahan L, Ogden AT, Natarajan RN, Fessler RG: A biomechanical evaluation of graded posterior element removal for treatment of lumbar stenosis: comparison of a minimally invasive approach with two standard laminectomy techniques. Spine (Phila Pa 1976) 34:17-23, 2009

4. Fessler RG, Khoo LT: Minimally invasive cervical microendoscopic foraminotomy: an initial clinical experience. Neurosurgery 51 (5 Suppl):S37-S45, 2002

5. Gambardella G, Gervasio O, Zaccone C: Approaches and surgical results in the treatment of ventral thoracic meningiomas. Review of our experience with a postero-lateral combined transpedicular-transarticular approach. Acta Neurochir (Wien) 145:385-392, 2003

6. Gandhi RH, German JW: Minimally invasive approach for 
the treatment of intradural spinal pathology. Neurosurg Focus 35(2):E5, 2013

7. Gottfried ON, Gluf W, Quinones-Hinojosa A, Kan P, Schmidt $\mathrm{MH}$ : Spinal meningiomas: surgical management and outcome. Neurosurg Focus 14(6):e2, 2003

8. Haji FA, Cenic A, Crevier L, Murty N, Reddy K: Minimally invasive approach for the resection of spinal neoplasm. Spine (Phila Pa 1976) 36:E1018-E1026, 2011

9. Iacoangeli M, Gladi M, Di Rienzo A, Dobran M, Alvaro L, Nocchi N, et al: Minimally invasive surgery for benign intradural extramedullary spinal meningiomas: experience of a single institution in a cohort of elderly patients and review of the literature. Clin Interv Aging 7:557-564, 2012

10. Khoo LT, Fessler RG: Microendoscopic decompressive laminotomy for the treatment of lumbar stenosis. Neurosurgery 51 (5 Suppl):S146-S154, 2002

11. King AT, Sharr MM, Gullan RW, Bartlett JR: Spinal meningiomas: a 20-year review. Br J Neurosurg 12:521-526, 1998

12. Kurland LT: The frequency of intracranial and intraspinal neoplasms in the resident population of Rochester, Minnesota. J Neurosurg 15:627-641, 1958

13. Levy WJ, Latchaw J, Hahn JF, Sawhny B, Bay J, Dohn DF: Spinal neurofibromas: a report of 66 cases and a comparison with meningiomas. Neurosurgery 18:331-334, 1986

14. Lu DC, Chou D, Mummaneni PV: A comparison of miniopen and open approaches for resection of thoracolumbar intradural spinal tumors. J Neurosurg Spine 14:758-764, 2011

15. McCormick PC: Anatomic principles of intradural spinal surgery. Clin Neurosurg 41:204-223, 1994

16. McCormick PC, Post KD, Stein BM: Intradural extramedullary tumors in adults. Neurosurg Clin N Am 1:591-608, 1990

17. McCormick PC, Stein BM: Miscellaneous intradural pathology. Neurosurg Clin N Am 1:687-699, 1990

18. Mehta AI, Adogwa O, Karikari IO, Thompson P, Verla T, Null UT, et al: Anatomical location dictating major surgical complications for intradural extramedullary spinal tumors: a 10-year single-institutional experience. J Neurosurg Spine 19:701-707, 2013

19. Mirimanoff RO, Dosoretz DE, Linggood RM, Ojemann RG, Martuza RL: Meningioma: analysis of recurrence and progression following neurosurgical resection. J Neurosurg 62:18-24, 1985

20. Nzokou A, Weil AG, Shedid D: Minimally invasive removal of thoracic and lumbar spinal tumors using a nonexpandable tubular retractor. J Neurosurg Spine 19:708-715, 2013

21. Ogden AT, Bresnahan L, Smith JS, Natarajan R, Fessler RG: Biomechanical comparison of traditional and minimally invasive intradural tumor exposures using finite element analysis. Clin Biomech (Bristol, Avon) 24:143-147, 2009

22. Pompili A, Caroli F, Telera S, Occhipinti E: Minimally invasive resection of intradural-extramedullary spinal neoplasms. Neurosurgery 59:E1152, 2006

23. Seppälä MT, Haltia MJ, Sankila RJ, Jääskeläinen JE, Heiskanen O: Long-term outcome after removal of spinal schwannoma: a clinicopathological study of 187 cases. J Neurosurg 83:621-626, 1995

24. Slin'ko EI, Al-Qashqish II: Intradural ventral and ventrolateral tumors of the spinal cord: surgical treatment and results. Neurosurg Focus 17(1):ECP2, 2004
25. Sloof JL, Kernohan JW, MacCarthy CS: Primary Intramedullary Tumors of the Spinal Cord and Filum Terminale. Philadelphia: Saunders, 1964

26. Smith ZA, Aoun SG, Y El Ahmadieh T, Wong AP, Lall RR, Bendok BR, et al: Minimally invasive resection of a highthoracic intradural extramedullary tumor: an operative 3-D video. Neurosurgery 73 (1 Suppl Operative):ons1, 2013 (Erratum in Neurosurgery 73:E913, 2013)

27. Smith ZA, Fessler RG: Nonexpandable tubular retractors and spinal tumors. J Neurosurg Spine 20:769-771, 2014 (Letter)

28. Smith ZA, Fessler RG: Paradigm changes in spine surgery: evolution of minimally invasive techniques. Nat Rev Neurol 8:443-450, 2012

29. Solero CL, Fornari M, Giombini S, Lasio G, Oliveri G, Cimino C, et al: Spinal meningiomas: review of 174 operated cases. Neurosurgery 25:153-160, 1989

30. Steck JC, Dietze DD, Fessler RG: Posterolateral approach to intradural extramedullary thoracic tumors. J Neurosurg 81:202-205, 1994

31. Stein CL, McCormick PC: Spinal intradural tumors, in Wilkins RH, Rengachary SS (eds): Neurosurgery. New York: McGraw-Hill, 1996

32. Traul DE, Shaffrey ME, Schiff D: Part I: spinal-cord neoplasms-intradural neoplasms. Lancet Oncol 8:35-45, 2007

33. Tredway TL, Santiago P, Hrubes MR, Song JK, Christie SD, Fessler RG: Minimally invasive resection of intraduralextramedullary spinal neoplasms. Neurosurgery 58 (1 Suppl):ONS52-ONS58, 2006

34. Wang MY, Cummock MD, Yu Y, Trivedi RA: An analysis of the differences in the acute hospitalization charges following minimally invasive versus open posterior lumbar interbody fusion. J Neurosurg Spine 12:694-699, 2010

35. Wong AP, Shih P, Smith TR, Slimack NP, Dahdaleh NS, Aoun SG, et al: Comparison of symptomatic cerebral spinal fluid leak between patients undergoing minimally invasive versus open lumbar foraminotomy, discectomy, or laminectomy. World Neurosurg 81:634-640, 2014

36. Zong S, Zeng G, Du L, Fang Y, Gao T, Zhao J: Treatment results in the different surgery of intradural extramedullary tumor of 122 cases. PLoS ONE 9:e111495, 2014

\section{Author Contributions}

Conception and design: Fessler, AP Wong, Lall, Dahdaleh, Lawton, Smith, Lam, Koski. Acquisition of data: AP Wong, Lall, Dahdaleh, Lawton, RH Wong, Harvey, Lam. Analysis and interpretation of data: Fessler, AP Wong, Lall, Dahdaleh, Lawton, Harvey, Lam, Koski. Drafting the article: Fessler, AP Wong, Lall, Dahdaleh, Lawton, Lam. Critically revising the article: Fessler, AP Wong, Lall, Dahdaleh, Lawton, Smith, RH Wong, Lam, Koski. Reviewed submitted version of manuscript: all authors. Statistical analysis: AP Wong, Lall, Lam. Administrative/technical/material support: AP Wong, Lall. Study supervision: Fessler, Lall.

\section{Correspondence}

Richard G. Fessler, Department of Neurosurgery, Rush University Medical Center, 1725 W. Harrison St., Ste. 855, Chicago, IL 60612. email: rfessler@rush.edu. 